\title{
Effectiveness of Self Instructional Module (SIM) on Knowledge Regarding Prevention of Cervical Cancer among Women at Selected Village, Tamil Nadu
}

\author{
Karthi.R ${ }^{1}$, M.Dhanalakshmi ${ }^{2}$, M.Elakkiya ${ }^{3}$, G.Dhivya ${ }^{4}$, M.Elumalai ${ }^{5}$, \\ K.Dhivyabharathi ${ }^{6}$, P.Ganagavallii ${ }^{7}$, VR.Gayathri ${ }^{8}$ \\ ${ }^{1}$ Professor \& HOD Dept of MSN, E.S College of Nursing, Tamilnadu \\ ${ }^{2-8}$ B.Sc., Nursing, E.S College of Nursing, Tamilnadu \\ Corresponding Author: Karthi.R
}

\begin{abstract}
Aim: to assess the effectiveness of self instructional module (SIM) on knowledge regarding prevention of cervical cancer among women

Objectives

i) To assess the pretest and post test level of knowledge of women regarding cervical cancer.

ii) To assess the effectiveness of self instructional module on cervical cancer among women at Villupuram.

iii) To find association between the post- tests knowledge scores with selected SocioDemographic variables among women.

Methods \& Material: A quantitative research approach-Pre-experimental one group pretest and post- test design was adopted. 50 samples were selected for the study by using non probability convenient sampling technique.

Results: The pretest mean 9.28 with the standard deviation of 2.23 and the post-test mean 21.62 with the standard deviation of 2.3; the mean difference between pretest and posttest is 12.34and standard error is 0.45 . the paired ' $t$ ' test value is 27.3 which is highly significant and it indicates that the Self instructional Module Improved the level of knowledge regarding cervical cancer among the women. Hence hypothesis $\mathrm{H} 1$ is accepted. The findings shows that there is no significant association between the knowledge of cervical cancer among women with selected socio demographic variables.
\end{abstract}

Conclusion: The study concluded that, selfinstructional module (SIM) on prevention of cervical cancer was effective in improving the knowledge level among women.

Key words: Cervical Cancer, Self instructional Module.

Cancer is a global problem. It is becoming a more challenging problem in both developed and developing countries. Cancer is the second leading cause of death in aging population. This may be due to increasing number of carcinogens, lack of skilled diagnosis and lack of medical care and lack of knowledge. As the cancer is a malignant disease, it attracted the public fear and concerns. Cancer in all forms is causing about $12 \%$ of death, throughout the world. India has the maximum number of cancer patients among all developing countries. One in every 14 Indian have at risk of developing cancer; more than 15 million people suffer from cancer at any point of time in India. About $6 \%$ of all deaths in India are due to cancers which contribute to $8 \%$ of global cancer mortality. The most common type of cancer in Indian women is cancer of cervix. Also among worldwide, cervical cancer is both the fourth most common cause of cancer and the fourth most common cause of death from cancer in women. 
Cervical cancer is a cancer arising from the cervix. It is due to the abnormal growth of cells that have the ability to invade or spread to other parts of the body. At early stage there are typically no symptoms. Later symptoms may include abnormal vaginal bleeding, pelvic pain or pain during sexual intercourse.

The early stages of cervical cancer may be completely free of symptoms. Vaginal bleeding, contact bleeding, or rarely a vaginal mass may indicate the presence of malignancy. Also, moderate pain during sexual intercourse and vaginal discharge are common symptoms of cervical cancer. Symptoms of advanced cervical cancer may include: loss of appetite, weight loss, fatigue, pelvic pain, back pain, leg pain, swollen legs, heavy vaginal bleeding, bone fractures, and rarely leakage of urine or feces from the vagina. Bleeding after touching, or after a pelvic exam is a common symptoms of cervical cancer. Even now the full causes of cervical cancer are known, however, and several other contributing factors have been implicated. Infection with some types of Human Papilloma Virus (HPV) is the greatest risk factor for cervical cancer, followed by smoking. Other risk factors include Human Immunodeficiency Virus (HIV), Oral contraceptives, and multiple pregnancies. Human Papilloma virus type 16 and 18 are the cause of $75 \%$ of cervical cancer globally while HPV 31 and 45 are the cause of another $10 \%$. Cigarette smoking, both active and passive, increases the risk of cervical cancer. Long-term use of oral contraceptives is associated with increased risk of cervical cancer. Women who have used oral contraceptives for 5to9 years have approximately three times the incidence of invasive cancer, and those who used them for 10 years or longer have approximately four times the risk. History of many pregnancies is associated with an increased risk of cervical cancer.

According to American cancer society the cancer of cervix is categorized into different stages like stage 0,stage1, stage 2 , stage 3 , stage 4 where stage 0 is tumor is found only in the layer of cells lining the cervix, stage 1 means cancer has invaded the cervix but has not spread anywhere else and this includes cancer that can be seen only under a microscope up to cancers more than 4 centimeters, where stage 2 cancer spread from the cervix but is still inside the pelvic area, in stage 3 cancer spreads to the lower part of the vagina or the pelvic wall and may be blocking the tubes that carry urine from the kidneys to the bladder and finally in the stage4 the cancer spread to nearby organs or other parts of the body.

Many screening programmes were implemented in developing countries since the early 1980's, yet it failed to reduce the mortality rates. The WHO in 2002 estimated that only $5 \%$ of women in developing countries are screened appropriately. Different countries have different cervical cancer screening recommendations. In, most of the countries they suggest screening between the ages group of 25-64. Screening is offered every 3 years from ages 25-49, every 5 years from ages 50-64 and in case of women of 65 age and above if they have not been screening since age 50 or had recent abnormal results. In the United States, screening is recommended for women between ages 21-65, regardless of age at sexual initiation or other high-risk behaviors.

Every year about 96,922 new cases of cervical cancer detected in India and 60,078 deaths were reported due to cervical cancer.3 Unfortunately, most women in India are not aware about the screening of cervical cancer which can be preventable and treatable. In view of magnitude of the problem, India has launched National Cancer Control Programme in 1975-76, which is now integrated with National Programme on Prevention and Control of Diabetes, Cardiovascular Disease and Stroke (NPCDCS). The services provided under this programme are health education, early detection and diagnosis, strengthening of existing institutions for palliative care. 2 
WHO urged the countries to lead the way towards elimination of cervical cancer by increasing coverage of human papilloma virus (HPV) vaccination, screening coverage with HPV testing, appropriate management of women who have screened positive and reduce mortality rates. 4 Despite all these programmes, Cervical cancer still remains a public health concern and a leading cause of cancer deaths in developing countries.

The National Cancer Control Programme for India was formulated with four major goals like primary prevention of tobacco related cancers; Early detection of the cancers of easily accessible sites; augmentation of treatment facilities; and establishment of an equitable pain control and palliative care network throughout the country. 21 Regional Cancer Centre's (RCCs) have been established under this programmed. Cancer care facilities are also available in many medical colleges and some private and charitable hospitals in the country. This programmed however has mainly contributed to the development of radiation oncology services rather than making any headway in the direction of prevention and early detection. There is no organized screening programmed for any of the common cancers in the country. Most cancer Centre's provide only opportunistic screening services.

\section{FOR THE STUDY Global}

In 2018 there were estimated 570,000 new cases of cervical cancer and 311,000 death from it worldwide. Much like HIV cervical cancer is a disease fueled by social, economic, and political, in equities. Lower income countries bear the highest burden with nearly $80 \%$ of all cervical cancer and $90 \%$ of death. Worldwide a cervical cancer affect 490,000 new women each year with more than 270,000 death (2017). About $85 \%$ of women dying from cervical cancer reside in developing countries.
According to Indian Council of Medical Research (ICMR) data on site specific cancer burden, in females, the common cancers are cervix, breast, mouth/oropharynx and esophagus. Cancer cervix is the leading cancer followed by breast cancer. The estimated number of breast cancer cases in India for the year 2025 and 2030 will be approximately 106, 124 and 123,634 respectively. The annual global incidence of carcinoma cervix is approximately 500,000 cases and India contributes about one-fifth of the burden, ie, 100,000 cases annually. In South India, cancer cervix is the most common cancer among females. The incidence of cancer cervix in Chennai is 99 per 100,000 . Over the years in spite of decreasing incidence of cervical cancers, the gynecologic cancers have increased in India and are contributing about $30 \%$ of total cancers among women in India. Among these carcinoma cervix followed by carcinoma ovary and corpus uterus are the major contributors.

Cervical cancer still remains a public health concern and a leading cause of cancer deaths in developing countries. Awareness about cervical cancer screening can improve women's approach to increased rate of early diagnosis and treatment of cervical cancer which can further reduce the morbidity and mortality. With this background this study was taken up to providing the information booklet the women in rural area will gain knowledge about the screening and prevention of cervical cancer.

\section{Statement of the Problem}

A study to assess the effectiveness of Self Instructional Module (SIM) on knowledge regarding prevention of cervical cancer among women at Selected Village, Villupuram district

\section{Objective}

$>$ To assess the pretest and post test level of knowledge of women between regarding cervical cancer.

$>$ To assess the effectiveness of self instructional module on cervical cancer among women. 
$>$ To find association between the posttests knowledge scores with selected Socio-Demographic variables among women.

\section{HYPOTHESIS}

H1 - There will be significant difference in the level of knowledge on cervical cancer among the women before and after creating awareness with self- instructional module (SIM).

H2 - There will be significant association between post- test knowledge on cervical cancer among women with their selected demographic variables.

\section{METHODS AND MATERIAL}

Quantitative research approach and Pre experimental one group pre-test and post test design adopted for this study. Women under the age group of 18-45 years were selected for the study. 50 Women selected by using non probability Purposive sampling technique.
Pretest knowledge level among Women was assessed by using Structured knowledge questionnaire regarding prevention of cervical cancer after the pretest the investigators distributed the Self Instructional Module regarding Prevention of Cervical Cancer after seven days posttest level of knowledge was assessed by using same knowledge questionnaire.

\section{RESULT AND DISCUSSION SECTION-II}

4.2. Assessment of the Pre and Post-Test Knowledge of Cervical Cancer among the Women.

Table 4.1 Shows that in pretest among 50 samples 35(70\%) had Inadequate level of knowledge, 15 (30) had Moderate level of knowledge and $0(0 \%)$ had adequate level of knowledge. In post test among 50 samples $0(0 \%)$ had Inadequate level of knowledge, 19 (38) had Moderate level of knowledge and $31(62 \%)$ had adequate level of knowledge.

Table 4.1: Frequency and percentage distribution of pre-test knowledge of cervical cancer among the women

\begin{tabular}{|l|c|c|c|c|}
\hline \multirow{2}{*}{ Level of Knowledge } & \multicolumn{2}{|c|}{ PRE TEST } & \multicolumn{2}{c|}{ POST TEST } \\
\cline { 2 - 5 } & Frequency & Percentage & Frequency & Percentage \\
\cline { 2 - 5 } & $\mathbf{N}$ & $\mathbf{N \%}$ & $\mathbf{N}$ & N\% \\
\hline Inadequate Knowledge & 35 & $70 \%$ & 0 & $0 \%$ \\
\hline Moderate Knowledge & 15 & $30 \%$ & 19 & $38 \%$ \\
\hline Adequate Knowledge & 0 & $0 \%$ & 31 & $62 \%$ \\
\hline
\end{tabular}

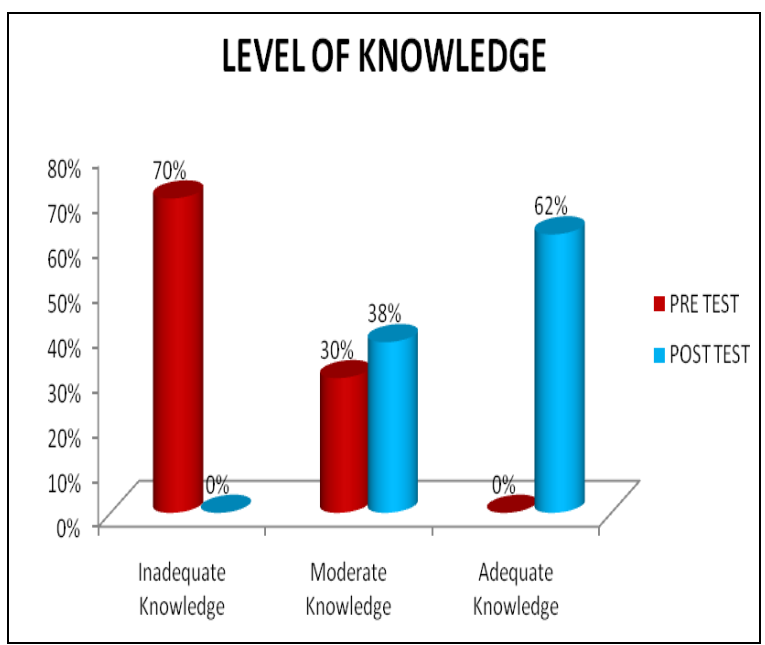

Effectiveness of Self Instructional Module (SIM) on Knowledge Regarding Prevention of Cervical Cancer among Women

Table 4.3: Reveals that the pre-test mean 9.28 with the standard deviation of 2.23 and the post-test mean 21.62 with the standard deviation of 2.3 ; the mean difference between pretest and post-test is 12.34and standard error is 0.45 . the paired ' $t$ ' test value is 27.3 which is highly significant and it indicates that there is improvement in knowledge regarding cervical cancer among the women.

Table 4.3: Effectiveness of Self Instructional module (SIM) on knowledge regarding prevention of cervical cancer among Women

\begin{tabular}{|c|c|c|c|c|c|c|}
\hline \multicolumn{2}{|c|}{ Pretest } & Post-test & $\begin{array}{c}\text { Mean } \\
\text { Difference }\end{array}$ & $\begin{array}{c}\text { Standard } \\
\text { error }\end{array}$ & $\begin{array}{c}\text { 'T' } \\
\text { Value }\end{array}$ \\
\hline Mean & SD & Mean & SD & (al \\
\hline 9.28 & 2.23 & 21.62 & 2.3 & 12.34 & 0.45 & $27.3 * \mathrm{HS}$ \\
\hline \multicolumn{7}{|c|}{$*$ Significant at $(\mathrm{p}<0.05)$} \\
\end{tabular}




\section{DISCUSSION}

The first objective of the study was to assess the pre test and post test level of knowledge of women between regarding cervical cancer.

Findings of pretest analysis revealed that majority $35(70 \%)$ had inadequate knowledge of $15(30 \%)$ had moderately adequate knowledge where as in the post test after the administration of Self Instructional module majority $31(65 \%)$ had adequate knowledge 19(38\%) had moderately adequate knowledge regarding prevention of cervical cancer among women,

This cross sectional study involved administrated questionnaire randomly selected of 500 women were participant sample 452 interviewed face to face. The questionnaire consisted in 14 questions relating participants 452 questionnaires were completed and included in the analysis the awareness of a sexually transmitted infection as a etiologic agent for cervical cancer was expressed by 175 (38.7\%) participants, the correct finality of the pap smear test by 308(68\%) and its recommended frequency by $176(38.7 \%)$ respondents. Among all participants, 125 $(27.7 \%)$ had undertaken the pap smear test at least once in their lifetime, $363(80.3 \%)$ were interested in receiving the anti HPV vaccine for themselves, $387(86 \%)$ for their daughters and 405(90\%) approved the introduction of the anti HPV vaccine in the national program of vaccination.

The second objective of the study is to assess the effectiveness of self instructional module on cervical cancer among women at Villupuram

The pre-test mean 9.28 with the standard deviation of 2.23 and the post-test mean 21.62 with the standard deviation of 2.3; the mean difference between pre and post-test is 12.34and standard error is 0.45 . the paired ' $t$ ' test value is 27.3 which is highly significant and it indicates that the Self instructional Module Improved the level of knowledge regarding cervical cancer among the women. Hence hypothesis $\mathrm{H}_{1}$ is accepted.

Third objective of the study was to find association between the post- tests knowledge scores with selected socio Demographic variables among women.

The findings shows that there is no significant association between the Post test level of knowledge regarding cervical cancer among women with selected socio demographic variables. Hence hypothesis $\mathrm{H}_{2}$ is rejected.

\section{CONCLUSION}

The study concluded with the result that the experimental group paired " $t$ " test value of the experiment group is 27.3 which is highly significant indicates that the effect to improve the knowledge regarding cervical cancer. Hence it concluded that, self-instructional module (SIM) on prevention of cervical cancer was effective in improving the knowledge level among women.

\section{Acknowledgement: None}

\section{Conflict of Interest: None}

Source of Funding: None

Ethical Approval: Approved

\section{BIBLIOGRAPHY}

1. Thovarayi SB, Noronha JA, Nayak S (2014) Knowledge of cervical cancer screening among rural Indian women: a cross sectional study. IOSR-JNHS 3(1): 51-55.

2. Aswathy S, Quereshi MA, Kurian B, Leelamoni K (2012) Cervical cancer screening: Current knowledge \& practice among women in a rural population of Kerala. IJMR 136(2): 205-210.

3. Siddharthar J, Rajkumar B, Deivasigamani $\mathrm{K}$ (2014) Knowledge, Awareness and Prevention of Cervical Cancer among Women Attending a Tertiary Care Hospital in Puducherry, India. Journal of clinic and diagnostic research 8(6): OC01-OC03.

4. Dutta DC (2008) Textbook of Gynaecology. 5th edition. New Delhi, new central book agency. 
5. Kumar HNH, Tanya S (2014) A Study on Knowledge and Screening for Cervical Cancer among Women in Mangalore City. Ann Med Health Sci Res 4(5): 751-756.

6. Saraiya M, Ahmed F, Krishnan $S$,et al. Cervical cancer incidence in a prevaccine era in the United states,1998 -2002.Obstet Gynecol.2007;109:360-370.

7. Park K. Cervical cancer, Park's Textbook of preventive and social medicine, $22^{\text {nd }}$ edition 2013:358-9.

8. Howkins \& Bourne. Carcinoma of cervix, Shaw's Textbook of Gynaecology, $15^{\text {th }}$ edition.2011; 399-416.

9. Aswathy S. Quereshi MA, Kurian B, Leelamoni K. Cervical cancer screening: Current knowledge \& practice among women in a rural population of Kerala, Indian J. Med. Res. 2012; 136(2):205-10.

10. Saha A, Chaudhary AN, Bhowmik P, Chatterjee R. Awareness of cervical cancer among Female students of premier colleges in Kolkata, India. Asian pac.J. Cancer prev. 2010;11:1085-90

11. Black MJ, Hokanson J. Medical Surgical Nursing $.7^{\text {th }}$ ed. Elsevier, 2010.

12. Jothula KY, Sreeharshika D. Knowledge regarding cervical cancer among married women in rural Telangana: a cross sectional study. International Journal of Research and Review. 2020; 7(5): 238-242.

13. Dahiya N, Aggarwal K, Singh MC, Garg S, Kumar R. Knowledge, attitude, and practice regarding the screening of cervical cancer among women in New Delhi, India. Tzu Chi Med J 2019; 31(4):240-3.

14. Islam JY, Khatun F, Alam A, Sultana F, Bhuiyan A, Alam $\mathrm{N}$ et al. Knowledge of cervical cancer and HPV vaccine in Bangladeshi women: a population based, cross-sectional study. BMC Women's Health, 2018; 18(15):1-13.
15. Nelson SB, Viswanathan N, Jenifer NA, Priyanka B. A cross-sectional study on cervical cancer and its prevention among women of age group 25- 50 years in a rural area of South Tamil Nadu, India. Int J Community Med Public Health 2018; 5:2536-41.

16. Patra S, Upadhyay M, Chhabra P. Awareness of cervical cancer and willingness to participate in screening program: Public health policy implications. J Can Res Ther 2017; 13:318-23.

17. Devi S, Goyal H. Cervical Cancer Knowledge among Women in Rural India. International Journal of Scientific \& Engineering Research, 2018; 9(3):1600-04.

18. Karunakaran U, The kkandathil N, Divakaran B, Joseph MM, Kannankai S, Kumaran JA. Cervical Cancer Screening Program-A Camp Based Cross Sectional Study among Rural Women in North Kerala. Science Journal of Public Health 2017; 5(3): 215-223.

19. Kosambiya RJ, Gohil A, Kamdar ZN, Patel PB, Modi A. Knowledge, Attitude and Practices about Cervical Cancer and Screening among Nurses of a Tertiary Care Centre in Western India. Natl J Community Med 2018; 9(6):391-95.

20. Gupta P, Kaveeshwar M, Patil A. Awareness and knowledge of cervical cancer in medical and paramedical staff-an observational study. Indian J ObstetGynecol Res 2020; 7(1):28-32.

How to cite this article: Karthi.R, M. Dhanalakshmi, M. Elakkiya et.al. Effectiveness of Self Instructional Module (SIM) on knowledge regarding prevention of cervical cancer among women at selected village, Tamil Nadu. International Journal of Science \& Healthcare Research. 2021; 6(2): 22-27. DOI: https://doi.org/10.52403/ijshr.20210405 